\title{
MOLECULAR CORRELATIONS IN LIQUID MONO- AND DIICHLOROALKANES
}

\author{
Z. BOCHYŃSKI AND H. DROZDowsKi \\ Non-Crystalline Materials Division, Institute of Physics, Adam Mickiewicz University \\ Grunwaldzka 6, 60-780 Poznań 2, Poland
}

(Received July 27, 1995; in final form December 5, 1995)

\begin{abstract}
This paper reports results of the X-ray diffraction structural studies of a series of liquid monochloroalkanes (chlorohexane, chlorooctane, chlorodecane, chlorododecane) and dichloroalkanes (1,6-dichlorohexane, 1,8-dichlorooctane, 1,10-dichlorodecane, 1,12-dichlorododecane) performed at 20 and $40^{\circ} \mathrm{C}$. From the X-ray diffraction patterns, obtained using Mo $K_{\alpha}$ radiation of the wavelength $\lambda=0.7107 \AA$, the mean angular distributions of intensities were determined. Then, the functions of radial distributions of electron density were numerically found using Fourier analysis. The mean structural parameters of the studied liquids (the inter- and intramolecular distances, the radii of coordination spheres, the coordination numbers) and the local arrangement of their molecules were established. The intermolecular arrangements in the studied liquid mono- and dichloroalkanes were found to be similar. Correlations were found between certain physical and chemical properties of the studied compounds and the spatial arrangement of their molecules.
\end{abstract}

PACS numbers: $61.25 . \mathrm{Em}$

\section{Introduction}

Neither monochloroalkanes (chlorohexane, chlorooctane, chlorodecane, chlorododecane) nor dichloroalkanes (1,6-dichlorohexane, 1,8-dichlorooctane, 1,10-dichlorodecane, 1,12-dichlorododecane) have been so far studied in the liquid state by the X-ray diffraction method. Structural data have only been reported for crystalline 1,6-dichlorohexane [1] belonging to the regular system with $a=7.58 \AA$.

This paper reports results of structural X-ray diffraction studies for four mono- and four dichloroalkanes (see Tables I and II).

The compounds to be studied of $99 \%$ purity were purchased from Aldrich-Chemie (Germany), Janssen Chimica (Belgium). 
TABLE I

Physical parameters of the studied liquid chloro- and dichloroalkanes.

\begin{tabular}{l|c|c|c|c|c}
\hline \multicolumn{1}{c|}{ Liquid } & $M[\mathrm{~g} / \mathrm{mol}]$ & \multicolumn{3}{|c|}{ Temperature $\left.{ }^{\circ} \mathrm{C}\right]$} & \multirow{2}{*}{$\left.d \mathrm{~g} / \mathrm{cm}^{3}\right]$} \\
\cline { 3 - 5 } & & $\begin{array}{c}\text { Melting } \\
\text { point }\end{array}$ & $\begin{array}{c}\text { Boiling } \\
\text { point }\end{array}$ & $\begin{array}{c}\text { Measured } \\
\text { point }\end{array}$ & \\
\hline chlorohexane & 120.62 & -94 & 136 & 20 & 0.879 \\
chlorooctane & 148.68 & -61 & 183 & 20 & 0.875 \\
chlorodecane & 176.73 & -34 & 223 & 20 & 0.868 \\
chlorododecane & 204.79 & -9 & 260 & 20 & 0.864 \\
\hline 1,6-dichlorohexane & 155.07 & -13 & 117 & 20 & 1.068 \\
& & & $10 \mathrm{hPa}$ & & \\
1,8-dichlorooctane & 183.12 & -8 & 242 & 20 & 1.026 \\
1,10-dichlorodecane & 211.18 & 15 & 142 & 20 & 0.999 \\
& & & $13 \mathrm{hPa}$ & & \\
1,12-dichlorododecane & 239.23 & 29 & 299 & 40 & 0.953
\end{tabular}

TABLE II

The effective electron numbers $\bar{K}_{m}$ and the average electron densities for the studied liquid chloro- and dichloroalkanes.

\begin{tabular}{l|c|c|c|r|c|c}
\hline \hline \multicolumn{1}{c|}{ Liquid } & $\bar{K}_{\mathrm{H}}$ & $\bar{K}_{\mathrm{C}}$ & $\bar{K}_{\mathrm{Cl}}$ & $\sum_{m} \bar{K}_{m}$ & $\sum_{m} Z_{m}$ & $\rho_{0}\left[\mathrm{el} / \AA^{3}\right]$ \\
\hline chlorohexane & 0.323 & 6.443 & 23.344 & 66.201 & 66 & 0.290 \\
chlorooctane & 0.327 & 6.595 & 23.925 & 82.244 & 82 & 0.291 \\
chlorodecane & 0.330 & 6.702 & 24.335 & 98.285 & 98 & 0.290 \\
chlorododecane & 0.333 & 6.782 & 24.641 & 114.350 & 114 & 0.292 \\
\hline 1,6-dichlorohexane & 0.309 & 5.942 & 21.444 & 82.557 & 82 & 0.342 \\
1,8-dichlorooctane & 0.314 & 6.124 & 22.137 & 98.604 & 98 & 0.333 \\
1,10-dichlorodecane & 0.318 & 6.264 & 22.669 & 114.656 & 114 & 0.327 \\
1,12-dichlorododecane & 0.321 & 6.375 & 23.091 & 130.710 & 130 & 0.314
\end{tabular}

\section{Experimental}

The wide-angle $\mathrm{X}$-ray diffraction patterns were obtained from digital recording by a VAG-24A printer coworking with a HZG-3 TuR automatic goniometer equipped with a graphite monochromator made at our laboratory [2]. A source of Mo $K_{\alpha}$ radiation of the wavelength $\lambda=0.7107 \AA$ was an X-ray tube working at the voltage $U=40 \mathrm{kV}$ and the current $I=30 \mathrm{~mA}$.

Measurements were carried out for the angles $3^{\circ} \leq \vartheta \leq 60^{\circ}$ at every $0.2^{\circ}$ (where $2 \vartheta$ is the scattering angle) by the transmission method $[3,4]$ with the incident and diffracted beams symmetric to each other with respect to the surface of the flat sample. The scattered radiation was detected by a VA-G-120 proportional counter coupled with a pulse detector and a line printer. 
Intensities of diffracted radiation were measured at $20^{\circ} \mathrm{C}$ and $40^{\circ} \mathrm{C}$. In the doubly thermostated cuvette with the studied liquid the temperature was stabilized to $\pm 0.1^{\circ} \mathrm{C}$ by using a flow-through thermostate.

\section{Calculations}

The radial distribution function of electron density $\rho(r)$ for a given liquid was determined from the modified Warren-Krutter-Morningstar equation [5] in the form

$$
4 \pi r^{2} \sum_{m} \bar{K}_{m} \rho(r)=4 \pi r^{2} \rho_{0} \sum_{m} \bar{K}_{m}+\frac{2 r}{\pi} \int_{0}^{\infty} S i(S) \sin (S r) \mathrm{d} S,
$$

where $K_{m}=f_{m} / f_{\mathrm{e}}$ is the effective number of diffracting electrons in the atom $m$, and

$$
f_{\mathrm{e}}=\sum_{m} f_{m} / \sum_{m} Z_{m}
$$

is the mean value of the atomic factor for a molecule per a single electron, $f_{m}$ is the atomic factor of the $m$-th atom and $Z_{m}$ is the number of electrons in the atom (see Table II).

The mean number of electrons in a unit volume $\left(1 \AA^{3}\right)$ is given by the formula $[6,7]$

$$
\rho_{0}=\left(d N 10^{-24} \sum_{m} \bar{K}_{m}\right) / M
$$

where $d$ is the macroscopic density of the liquid, $N$ - the Avogadro number and $M$ - molecular mass (see Table I). The summation in Eq. (1) runs over all atoms of the molecule

$$
\sum_{m} \bar{K}_{m}=n_{\mathrm{C}} \bar{K}_{\mathrm{C}}+n_{\mathrm{H}} \bar{K}_{\mathrm{H}}+n_{\mathrm{Cl}} \bar{K}_{\mathrm{Cl}} \text {, }
$$

where $n_{\mathrm{C}}, n_{\mathrm{H}}$ and $n_{\mathrm{Cl}}$ are the numbers of carbon, hydrogen and chlorine atoms, respectively, in one molecule, and $\bar{K}_{\mathrm{C}}, \bar{K}_{\mathrm{H}}$, and $\bar{K}_{\mathrm{Cl}}$, are the average effective numbers of electrons in the atoms of carbon, hydrogen and chlorine.

The mean effective number of diffracting electrons was found from the integral average

$$
\bar{K}_{m}=\frac{1}{S_{2}-S_{1}} \int_{S_{1}}^{S_{2}} K_{m} \mathrm{~d} S,
$$

where $S=4 \pi \sin \vartheta / \lambda, \lambda$ is the wavelength and $\vartheta-$ the Bragg angle. The calculations have been performed for a finite range of $S$ values from $S_{1}=0.43$ to $S_{2}=15.31 \AA^{-1}$. The value of $i(S)$ given by

$$
i(S)=\left[\bar{I}(S) / N-\sum_{m} f_{m}^{2}\right] / f_{\mathrm{e}}^{2},
$$

where $\bar{I}(S) / N$ is the experimentally observed total coherent intensity of scattered radiation per one structural unit, $\sum_{m} f_{m}^{2}$ denotes the theoretical independent scattering on atoms of one structural unit, $f_{\mathrm{e}}$ is a sharpening factor, often written in the form (2). In order to determine $i(S)$ from the experimental data, $\bar{I}(S) / N$ and 
$\sum_{m} f_{m}^{2}$ must be given in the same units. The integrals appearing in the expression for $\rho(r)$ were found numerically by the Simpson method for $0 \leq r \leq 20 \AA$ at every $0.05 \AA$.

Corrections for the background, polarization [8, 9], absorption [10] and the Compton scattering were taken into account in the mean angular distributions of the scattered radiation which were subsequently normalized following the Norman criterion [11]. The calculations were performed using a special software for structural studies of molecular liquids [12]. The maximum experimental error in determination of radial distribution function was estimated to be $\pm 3 \%$.

\section{Results and discussion}

Fourier analysis of the angular functions of intensity $\bar{I}(S)$ (Figs. 1-3) yielded the functions of radial distribution of electron densities, shown in Fig. 4a-d.

The main maximum of the angular functions of intensity distribution occurs at the same positions $S_{1}=(1.36 \pm 0.02) \AA^{-1}$ for all monochloroalkanes studied.

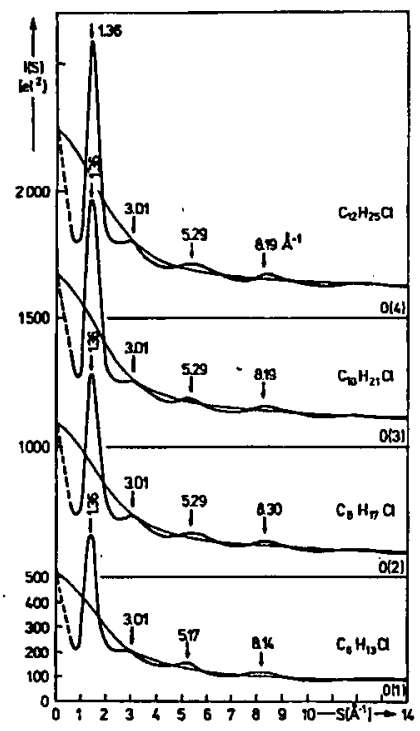

Fig. 1. The normalized functions of angular distribution of intensity obtained for chlorohexane, chlorooctane, chlorodecane and chlorododecane using a Mo $K_{\bar{\alpha}}$ radiation source $(\lambda=0.7107 \AA)$ together with the independent intensity.

This value corresponds to the mean interatomic distance found from the Bragg equation $[13,14] \bar{d}=4.63 \AA$.

For the dichloroalkanes the main maximum occurs at $S_{1}=(1.42 \pm 0.02) \AA^{-1}$ (Figs. 2 and 3 ), which corresponds to the mean distance between the scattering centres $\vec{d}=4.43 \AA[15,16]$.

The shortest mean intermolecular distance is $5.38 \AA$ for the monochloroalkanes and $5.14 \AA$ for the dichloroalkanes studied: 

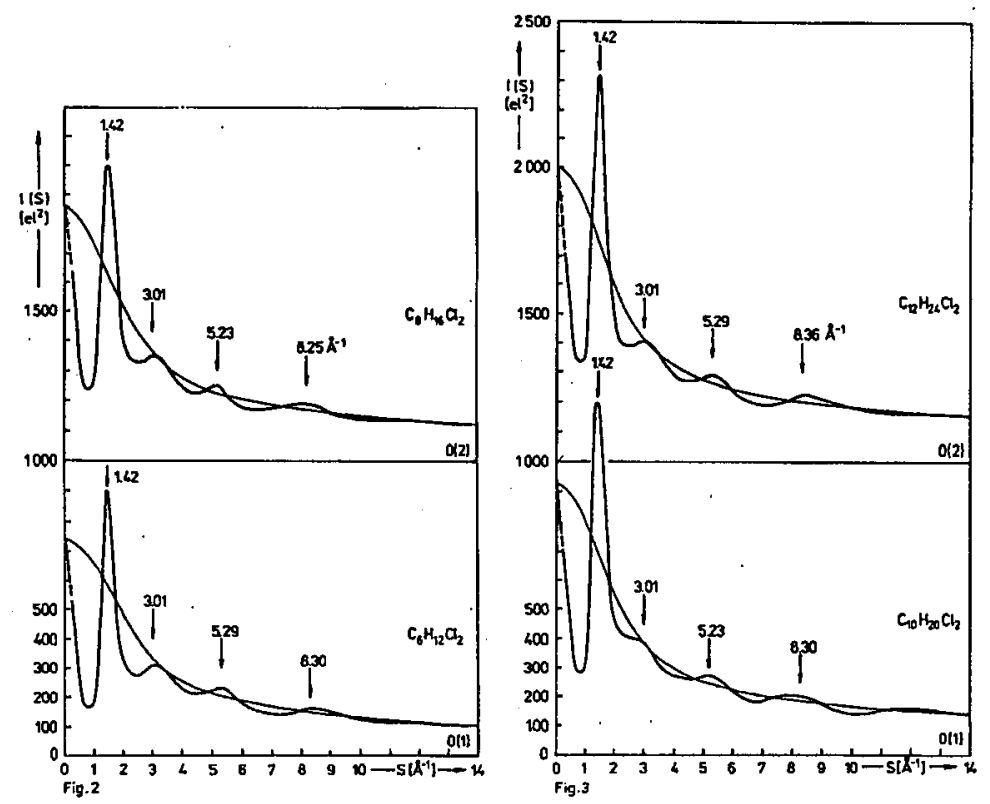

Fig. 2. The normalized functions of angular distribution of intensity obtained for 1,6-dichlorohexane and 1,8-dichlorooctane using a Mo $K_{\bar{\alpha}}$ radiation source $(\lambda=$ $0.7107 \AA$ ) together with the independent intensity

Fig. 3. The normalized functions of angular distribution of intensity obtained for 1.10-dichlorodecane and 1,12-dichlorododecane using a Mo $K_{\dot{\alpha}}$ radiation source $(\lambda=$ $0.7107 \AA$ ) together with independent intensity.

The differential functions of radial distribution of electrons, Fig. 4a-d, reveal three broad maxima in the range of $\bar{r} \approx 3-20 \AA$, which have been ascribed to three subsequent spheres of intermolecular ordering [17]. The spread of each sphere and the coordination numbers of molecules (Table III) have been determined.

The mean coordination numbers decrease with the homologous series of mono- and dichloroalkanes which has been observed for all three spheres. The microscopic densities of monochloroalkanes take values from $0.879\left(\mathrm{C}_{6} \mathrm{H}_{13} \mathrm{Cl}\right)$ to $0.864 \mathrm{~g} / \mathrm{cm}^{3}\left(\mathrm{C}_{12} \mathrm{H}_{25} \mathrm{Cl}\right)$, while the densities of dichloroalkanes from 1.068 $\left(\mathrm{C}_{6} \mathrm{H}_{12} \mathrm{Cl}_{2}\right)$ to $0.953 \mathrm{~g} / \mathrm{cm}^{3}\left(\mathrm{C}_{12} \mathrm{H}_{24} \mathrm{Cl}_{2}\right)$. The molecular mass of mono- and dichloroalkanes increases with the homologous series from $120.62\left(\mathrm{C}_{6} \mathrm{H}_{13} \mathrm{Cl}\right)$ to $239.23 \mathrm{~g} / \mathrm{mol}\left(\mathrm{C}_{12} \mathrm{H}_{24} \mathrm{Cl}_{2}\right)$. This means that the same volume of a given compound comprises a greater number of lighter molecules than heavier ones. This explains the decrease in the mean number of neighbouring molecules with increasing length of the aliphatic chain (Table III).

The shape of the radial function in the 1st coordination sphere, ranging on the average from 3.20 to $7.50 \AA$, with a maximum at $\bar{r} \approx 5.10 \AA$, indicates that the parallel coordination is dominant for $\bar{r} \approx 4.2-5.4 \AA$ for all studied mono- and dichloroalkanes. There are three variants of the parallel coordination: with chains 

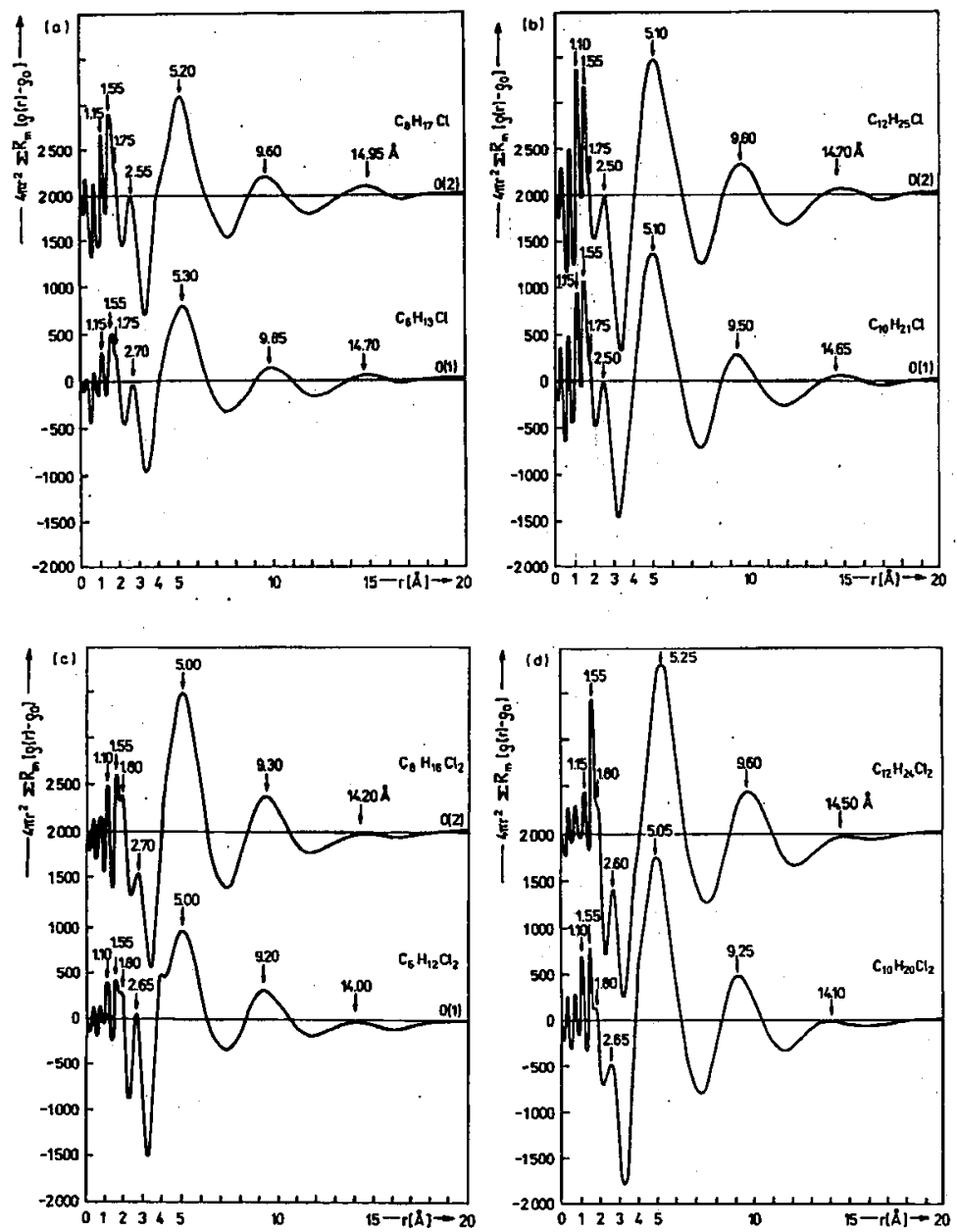

Fig. 4. The differential radial distribution functions for: (a) chlorohexane and chlorooctane, (b) chlorodecane and chlorododecane, (c) 1,6-dichlorohexane and 1,8-dichlorooctane, (d) 1,10-dichlorodecane and 1,12-dichlorododecane.

side by side, with one chain shifted by about $2.5 \AA$ along the chain axis with respect to the other one, and with the chains at the right angle to one another.

The contribution of an aliphatic chain to the whole volume of the sphere increases as its length increases from about $46.3 \%\left(\mathrm{C}_{6} \mathrm{H}_{12} \mathrm{Cl}_{2}\right)$ to about $55.3 \%$ $\left(\mathrm{C}_{12} \mathrm{H}_{24} \mathrm{Cl}_{2}\right)$. The contribution of chlorine atoms to the volume of the sphere decreases from $\approx 14.5 \%\left(\mathrm{C}_{6} \mathrm{H}_{12} \mathrm{Cl}_{2}\right)$ to $\approx 8.6 \%\left(\mathrm{C}_{12} \mathrm{H}_{24} \mathrm{Cl}_{2}\right)$.

\section{Conclusions}

The functions of angular distribution of scattered radiation intensity and the functions of radial distribution of electron density obtained for all studied liquids 
TABLE III

The spread of coordination spheres and the number of molecules in each sphere for the studied chloro- and dichloroalkanes.

\begin{tabular}{|c|c|c|c|}
\hline \multirow[b]{3}{*}{ Liquid } & \multicolumn{3}{|c|}{ Sphere } \\
\hline & I & II & III \\
\hline & $\begin{array}{c}\text { Range } \\
{[\AA]} \\
\text { (number of } \\
\text { molecules) }\end{array}$ & $\begin{array}{c}\text { Range } \\
{[\AA]} \\
\text { (number of } \\
\text { molecules) }\end{array}$ & $\begin{array}{c}\text { Range } \\
{[\AA]} \\
\text { (number of } \\
\text { molecules) }\end{array}$ \\
\hline chlorohexane & $\begin{array}{c}3.30-7.55 \\
(7.6)\end{array}$ & $\begin{array}{c}7.55-12.10 \\
(24.6)\end{array}$ & $\begin{array}{c}12.10-16.50 \\
(50.7)\end{array}$ \\
\hline chlorooctane & $\begin{array}{c}3.20-7.50 \\
(5.9)\end{array}$ & $\begin{array}{c}7.50-11.90 \\
(18.8)\end{array}$ & $\begin{array}{c}11.90-16.60 \\
(42.9)\end{array}$ \\
\hline chlorodecane & $\begin{array}{c}3.25-7.45 \\
(4.8)\end{array}$ & $\begin{array}{c}7.45-11.80 \\
(15.2)\end{array}$ & $\begin{array}{c}11.80-16.65 \\
(37.3)\end{array}$ \\
\hline chlorododecane & $\begin{array}{c}3.30-7.50 \\
(4.3)\end{array}$ & $\begin{array}{c}7.50-12.00 \\
(14.1)\end{array}$ & $\begin{array}{c}12.00-16.75 \\
(31.8)\end{array}$ \\
\hline $\begin{array}{c}\text { 1,6-dichloro- } \\
\text { hexane }\end{array}$ & $\begin{array}{c}3.15-7.30 \\
(6.3)\end{array}$ & $\begin{array}{c}7.30-11.70 \\
(21.0)\end{array}$ & $\begin{array}{c}11.70-16.20 \\
(45.7)\end{array}$ \\
\hline $\begin{array}{l}\text { 1,8-dichloro- } \\
\text { octane }\end{array}$ & $\begin{array}{c}3.20-7.35 \\
\quad(5.4)\end{array}$ & $\begin{array}{c}7.35-11.55 \\
(16.0)\end{array}$ & $\begin{array}{c}11.55-16.10 \\
(37.0)\end{array}$ \\
\hline $\begin{array}{c}\text { 1,10-dichloro- } \\
\text { decane }\end{array}$ & $\begin{array}{c}3.15-7.30 \\
(4.3)\end{array}$ & $\begin{array}{c}7.30-11.60 \\
(13.70)\end{array}$ & $\begin{array}{c}11.60-16.05 \\
(29.7)\end{array}$ \\
\hline $\begin{array}{l}\text { 1,12-dichloro- } \\
\text { dodecane }\end{array}$ & $\begin{array}{c}3.15-7.40 \\
(4.0)\end{array}$ & $\begin{array}{c}7.40-12.10 \\
(13.2)\end{array}$ & $\begin{array}{c}12.10-16.15 \\
(23.1)\end{array}$ \\
\hline
\end{tabular}

reveal clearly marked maxima which indicates the presence of short range ordering in these liquids.

The applied methods of measurements and calculations permitted determination of the mean structural parameters (the inter- and intramolecular distances, the radii of coordination spheres, the coordination numbers) and local ordering of the molecules in the studied liquids in the range $1 \leq r \leq 20 \AA$. The interand intramolecular distances were calculated with the accuracies $\Delta r= \pm 0.01$ and $\pm 0.05 \AA$, respectively. The maxima on the differential functions of radial distribution have been ascribed to the following pairs of atoms: $\mathrm{C}(1)-\mathrm{H}(1)=1.10 \AA$, $\mathrm{C}(1)-\mathrm{C}(2)=1.55 \AA, \mathrm{C}(1)-\mathrm{Cl}=1.75 \AA, \mathrm{C}(1)-\mathrm{C}(3)=2.55 \AA$ and $\mathrm{C}(2)-\mathrm{Cl}=2.70 \AA$.

The radial distribution functions of electron density are charged with a certain error following from the application of the integral Fourier formula derived for infinite limits of integration to an experimental situation in which measurements 
are conducted in a finite range of argument values. Replacement of the Fourier transform from Eq. (5) by the proper integral in Eq. (4) implies the appearance of additional oscillations for $0 \leq r \leq 1 \AA$. These maxima have no physical meaning and are only a mathematical effect, a consequence of the applied approximations.

The dominant effect on the local structure of the liquid mono- and dichloroalkanes is exerted by the shape and length of the aliphatic chain. The proposed parallel coordination of molecules is similar in all studied liquids and depends on mutual orientations of the aliphatic chains of the neighbouring molecules.

A decrease in the mean coordination numbers and an increase in the mean intermolecular distances is interpreted as related to changes in the macroscopic parameters of the liquids.

The use of short-wave radiation from an X-ray tube with a molybdenum anode permitted determination of the spheres of intermolecular ordering, that is the supermolecular structure in the studied liquids.

A relation between the structural parameters of the liquids determined from the experiment (arrangement of molecules in spheres) and their physical and chemical parameters (such as macroscopic density, electron density, melting and boiling points) has been confirmed.

The work was performed within the research project No. 201319101 of the Committee for Scientific Research.

\section{References}

[1] K. Kojima, K. Sahashita, Y. Takeishi, Bull. Chem. Soc. Japan 27, 287 (1954).

[2] Z. Bochyniski, Progress Report for the Physics Committee of the Polish Academy of Sciences, Warszawa 1974.

[3] H.M. James, T.A. Keenan, J. Chem. Phys. 31, 12 (1959).

[4] Z. Bochyriski, Acta Phys. Pol. A 34, 185 (1968).

[5] B.E. Warren, H. Krutter, O. Morningstar, J. Am. Ceram. Soc. 19, 202 (1936).

[6] Y. Waseda, The Structure of Non-Crystalline Materials, McGraw-Hill, New York 1979.

[7] W. Kast, Koll. Z. 120, 40 (1952).

[8] K. Sagel, Tabellen zur Röntgenstrukturanalyse, Springer-Verlag, Berlin 1958.

[9] D.W. Hukins, X-ray Diffraction by Disordered and Ordered Systems, Pergamon Press, London 1981.

[10] P. Schwager, K. Bartels, R. Hubner, Acta Crystallogr. A 29, 291 (1973).

[11] N. Norman, Acta Crystallogr. 10, 370 (1957).

[12] H. Drozdowski, Ph.D. thesis, UAM, Poznan 1994.

[13] H.P. Klug, L.E. Alexander, X-ray Diffraction Procedures for Polycrystalline and Amorphous Materials, Wiley, New York 1966.

[14] H. Brasseur, Les rayons $X$ et leurs applications, Editions Desoer, Liège 1974.

[15] P.J. Wheatley, The Determination of Molecular Structure, Oxford University Press, Oxford 1959.

[16] J.L. Karle, J. Chem. Phys. 20, 65 (1952).

[17] A.Z. Golik, A.F. Skryshevskii, I.I. Adamenko, Zh. Strukt. Khim. 8, 1015 (1967). 